\title{
MODIFICATION OF RICE BRAN OIL WITH MALEICANHYDRIDE USING MICROWAVE TECHNIQUE
}

\author{
R. Tiwari $^{1}$, P. Agrawal ${ }^{1}$, V. Y. Karadbhajne ${ }^{2}$ \\ 1.Department of Chemistry 2. Department of Oil Technology \\ Laxminarayan Institute of Technology RTM, Nagpur University Amravati \\ Road Nagpur 440033, (India).
}

\begin{abstract}
:
Modification in development of uses of rice bran oil by doing its malenization using maleic anhydride with the help of microwave theory. Taking different proportions of oil and malenizing it thereby increases its molecular weight which enhances its stability and usability. In nutshell providing the new opportunity and experiments on malenized rice bran oil. In the present work rice bran oil was malenized using maleic anhydride. Reaction conditions such as time of reaction, order of addition and temperature have been standardized to get a resin of desired molecular weight, HLB ratio and other parameters. This material can be used as a replacer for petroleum origin, raw materials used in manufacturing of various surfactants. This material is ecofriendly as they are straight chain obtained from vegetable origin.
\end{abstract}

Key Words: Malenized Oil, Rice Bran Oil, Maleic Anhydride.

\section{INTRODUCTION :}

Rice bran oil (also known as rice bran extract) is the oil extracted from the germ and inner husk of rice. Rice bran oil has a composition similar to that of peanut oil, with $38 \%$ monounsaturated, $37 \%$ polyunsaturated and $25 \%$ saturated fatty acids. Rice bran oil, iodine number 99-108, contains internal double bonds in its oleic, linoleic acid components. The unsaturation is high enough to give the oil the classical terminology of "semidrying" but not high enough to allow its use as a traditional "drying oil". A number of methods have been suggested for the improvement of the properties of oils such as the shifting of non-conjugated double bonds to conjugated form (isomerisation) and removal of water to introduce a new double bond (dehydration). There is another method of adding unsaturated compound to the unsaturated part of 
the oil molecule, thus increasing its complexity and heat reactivity. So for the modification of oil, it is treated with maleic anhydride and hence the modified oil is known as malenized oil and the process is known as malenization. Malenization of seed oil has been known for a long time. In malenization, the maleic is attached near the unsaturated section of fatty acid radical, it slightly retards oxidation so that the maleic treated oils do not show greatly increased air-drying properties. However, they are definitely faster bodying with better hue and with uniform viscosity and better water resistance in the dried films.

Maleic anhydride is a dibasic acid which reacts with both conjugated and isolated double bonds. When the oil is heated and malenized with maleic anhydride, the mono unsaturated fatty acids present in oil reacts with maleic anhydride by "ene reaction", resulting in the addition of succinic anhydride group to the allylic position of the fatty acid. The mechanism involves an allylic shift of one double bond by transferring the allylic hydrogen to the enophile and bonding of the two molecules. The diunsaturated, non conjugated fatty acids, present in oil, also follows the ene reaction, and results in conjugation of the two double bonds. This adduct now undergoes a Diels-Alder reaction with another mole of maleic anhydride.

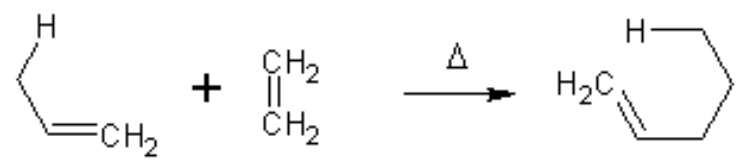

Systematic representation of ene reaction

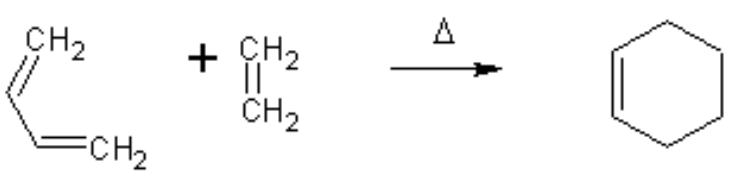

Systematic representation of Diel's Alder Reaction

Now in di unsaturated, non- conjugated fatty acid, each double bond has two allylic positions and one or the other but not both can undergo "ene reaction". Thus, in a hypothetical triglyceride containing two mono and one diunsaturated fatty acid, the maximum number of anhydride groups that can be introduced per triglyceride is four. In the 
present work, we are malenizing rice bran oil by treating it with maleic anhydride using microwave theory. The experimental conditions such as time of reaction, order of addition and temperature are being set. This malenized rice bran oil can be used as a replacer for petroleum origin, raw materials used in manufacturing of various surfactants.

\section{CHEMISTRY AND MECHANISM:}

Rice bran oil contains internal double bonds in its oleic and linoleic acid. During malenization of rice bran oil, maleic anhydride is reacted with double bonds present in oleic acid by ene-reaction path resulting in the addition of a succinic anhydride group to the allylic position of the oleic acid. The overall reaction is carried out at $210^{\circ} \mathrm{C}$. The mechanism involves an allylic shift of double bond by transferring the allylic hydrogen to the enophile and bonding of two molecules is as shown below:-

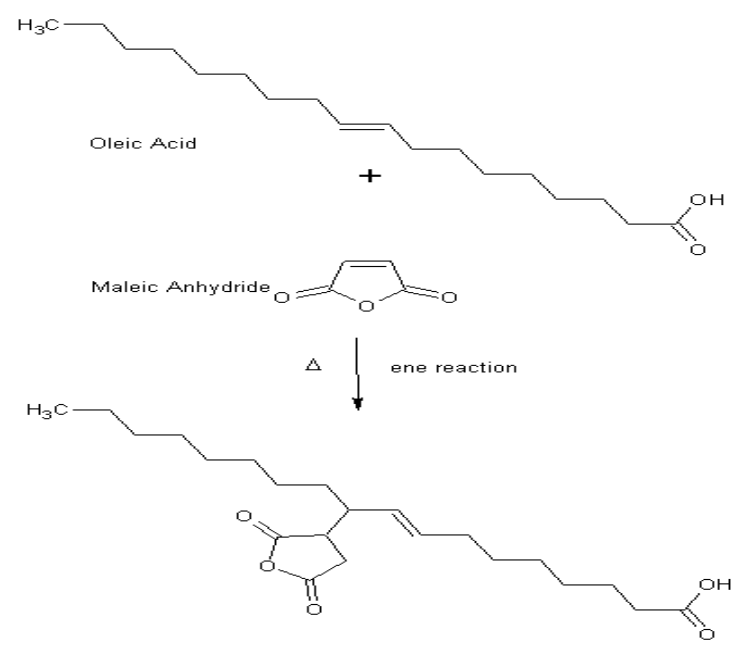

Now linoleic acid present in rice bran oil has non-conjugated double bonds . during malenization ene-reaction also takes place between linoleic acid and maleic anhydride resulting in conjugation of two double bonds. This adduct now undergoes Diels-Alder reaction with another mole of maleic anhydride. The mechanism of Diels-Alder reaction is a simultaneous cyclic movement of six electrons: four in the 
diene and two in dienophile. The overall reaction of maleic anhydridewith linoleic acid is as shown below:-

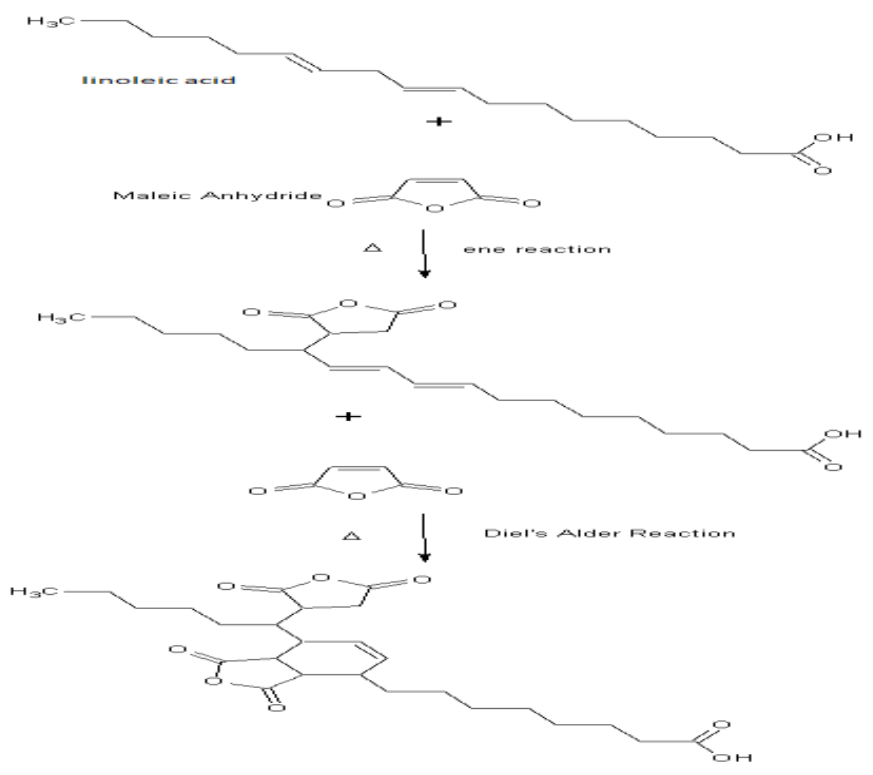

Thus in Rice bran oil, a hypothetical triglyceride containing one mono and one diunsaturated fatty acid, the maximum number of anhydride groups that can be introduced per triglyceride is three.

\section{INFORMATION IN DETAIL ABOUT THE INSTRUMENT USED:}

The CEM Focused Microwave TM Synthesis System, Discover $\mathrm{S}$ is designed to enhance the ability to perform chemical reactions under controlled conditions on a laboratory scale. The system facilitates either homogenous or heterogeneous solution phase chemistry, solid phase chemistry or chemistry conducted on solid supports. It accommodates vessels ranging in working volume from $5 \mathrm{~mL}$ to $125 \mathrm{~mL}$ for reactions performed under atmospheric conditions and $10 \mathrm{~mL}$ or 35 $\mathrm{mL}$ vessels with septa in addition to $80 \mathrm{~mL}$ vessels for reactions performed at elevated temperature and pressure. Primary uses of the Discover are in the discovery and lead optimization phases of the new product development process. 
Microwave energy has long been used for Polymer Chemistry, both in monomer synthesis and polymerizations. It has been proven to reduce side reactions, shorten overall reaction time, and generate a better overall polymer yield. Microwave energy has been used for:

Free radical polymerization

Step-growth polymerizations

Living radical polymerization

Ring opening polymerizations

Sol-gel

polymerizations

..And many more.......

\section{Equipment}

Instrument: CEM Discover S System

Temperature: $50-300{ }^{\circ} \mathrm{C}$

Pressure range: Atmospheric-21 bar Power range: $0-300 \mathrm{~W}$ at $2.45 \mathrm{MHz}$ Agitation: Magnetic stirrer

\section{CEM Microwave Manual}

1. Place all reagents into $10 \mathrm{~mL}$, or $35 \mathrm{~mL}$ vial with a stir bar.

2. Seal the vessel using the supplied cap, with the notches positioned downward.

Position cap above vessel with the notches pointing down.

Place cap on top of vessel at a slight angle and roll your finger over the top of the vessel.

- Press down until a click is audible, indicating the top is properly positioned.

3. Ensure that cavity is clean and empty.

4. Open the Synergy software.

5. Parameters:

Mode - Explorer

Explorer - Explorer 12

Explorer - Hybrid rack : $2(35 \mathrm{ml})$ and $5(10 \mathrm{ml})$

Options - Temperature - Infrared 
6. With the rack locked into position in the autosampler tray, place the vial(s) into the

Explorer rack.

7. Select (highlight) the method to be added to the rack.

Details regarding the method types and method programming are outlined in the

Explorer Operation Manual.

8. "Double click" the desired rack position in which to add the method.

9. Press the PLAY key located at the top of the Synergy screen.

The autosampler will automatically load the selected vessel(s) and send the method parameters to Discover.

The pressure device will automatically move into position prior the microwave radiation.

Method parameters can be changed during a reaction by using the hot keys.

\section{Removing the vessel:}

1. When the reaction is complete, the reaction vessel will cool until the release parameters are achieved. Once these parameters are attained, the pressure device automatically releases and moves to its home position. The sample is returned to the Explorer rack.

2. If the APD does not automatically release the reaction vessel, the pressure (or temperature) is above the release limit. A message will appear indicating the current temperature and pressure value. Cool the reaction vessel completely, and manually release the APD. Once the APD is in its home position, remove the vessel from microwave cavity, and place it in a fume hood or other ventilated area. Caution: To prevent the possibility of severe burns, wear insulate gloves and protective gear as outlined in the user's safety program. Contents of the vail(s) may be under pressure and should be released within a fume hood.

3. After the vial has been returned to the Explorer rack, the cap can be removed and work up can be performed. 


\section{EXPERIMENTAL WORK:}

First of all test of stability of rice bran at room temperature was carried out i.e. acid value test was carried out.

\section{Malenization of rice bran oil}

It was done in following steps:

1) Prepared a mixture of rice bran oil and maleic anhydride in the ratio of $85: 15$, the mixture was heated up to $70^{\circ} \mathrm{C}$ for 10 minutes.

Then the acid value test was again carried out.

2) Then that $100 \mathrm{~g}$ prepared mixture was divided into five equal parts in small conical flasks and these bottles with its samples were placed one by one into microwave synthesis reactor at different parameters. Acid value of each batch is calculated.

Table No.1: Table of samples set at different parameters:

\begin{tabular}{|c|c|c|c|}
\hline SAMPLES & $\begin{array}{c}\text { TIME } \\
\text { (MIN) }\end{array}$ & $\begin{array}{c}\text { MICROWAVE } \\
\text { POWER (WATT) }\end{array}$ & $\begin{array}{c}\text { TEMPERATURE } \\
\left({ }^{\circ} \mathbf{C}\right)\end{array}$ \\
\hline 1 & 5 & 100 & 125 \\
\hline 2 & 5 & 125 & 140 \\
\hline 3 & 7 & 90 & 110 \\
\hline 4 & 5 & 130 & 150 \\
\hline 5 & 7 & 125 & 140 \\
\hline
\end{tabular}

\section{Table No.2: Acid Value Calculation}

\begin{tabular}{|c|c|}
\hline SAMPLES & ACID VALUE \\
\hline 1 & 47.408 \\
\hline 2 & 44.82 \\
\hline 3 & 62.48 \\
\hline 4 & 48.1263 \\
\hline 5 & 116.37 \\
\hline
\end{tabular}

As clear from the data sample 2 is having lowest acid value ${ }^{1}$, which means maximum number of conversion is formed at this level, so sample 2 was selected for the further experiments.

Also the selected malenized was tested for its various Physicochemical properties.

\section{RESULT AND DISCUSSION:}

Table No. 3: Physico-Chemical Properties of Malenized Oil 


\begin{tabular}{|c|c|c|}
\hline $\begin{array}{l}\text { Sr. } \\
\text { No. }\end{array}$ & $\begin{array}{c}\text { Physico - Chemical } \\
\text { Property }\end{array}$ & Observation \\
\hline 1 & Acid value of resin & 44.82 \\
\hline 2 & $\mathrm{PH}$ value & 2.12 \\
\hline 3 & Solid (\%) & 89.86 \\
\hline 4 & $\begin{array}{l}\text { Solubility of Polymer } \\
\text { i) In water } \\
\text { ii) In alcohol + water }\end{array}$ & $\begin{array}{l}\text { Insoluble Partially Soluble Partially } \\
\text { Soluble }\end{array}$ \\
\hline 5 & Molecular Weight of Resin & 2560 \\
\hline 6 & $\begin{array}{l}\text { Viscosity (By Ford Cup } \\
\text { Method) (70:30) }\end{array}$ & $250 \mathrm{Sec}$. \\
\hline 7. & HLB Ratio & 13.9 \\
\hline
\end{tabular}

\section{Conclusion:}

The malenized rice bran oil prepared by using microwave technique has acid value 44.82, $\mathrm{PH}$ value 2.12 and molecular weight 2560 so it can be used as a base material for surfactants $^{9}$, paints, replacer for petroleum origin etc. the main reason for it are as follows: in today's world competition, fast communication, advancement in Research and Development and many more, providing a vast platform for growth of useful things for masses. The globalization has given a world a beautiful scenario of success and fast growth but on the other hand it has also lead to fast consumption of our natural resources to a very large extent leaving a scarcity to be full filled. But naturally full filling this scarcity will surely take hundreds of years. This question has widely diversified the Research and Development activities all over the world to work for modifying current natural resources to be useful for masses. A Renewable and Non Renewable source has formed a very wide gap now days. As globalization and increased world population is leading world towards extinction of non renewable source mainly petroleum. This scarcity can only be full filled by modifying renewable sources to such a level that it can match up in its properties, quality and other properties with non 
renewable source. Use of modified Rice bran oil in the form of Malenized oil in paints, powder detergent, liquid detergent and cake detergent will certainly open up a new page in promoting "Green Chemistry and Pollution free Natural Vegetable Products"

\section{References:}

ASTM Standard method, (1981). 6.01, D 1639-70, (For acid value of organic Coating Materials), Published by the American society for testing materials, Philadelphia.

ASTM Standard method, (1979). 6.03, D 1959-69, (for Iodine Value of drying oils, varnishes, Resins).

ASTM Standard method, (1979). 6.03, D 1952-67, (For Saponification value of Drying oils).

AOCS, (1946). Official and Tentative Methods of the American oil chemical's Society $2^{\text {nd }}$ edition Cd 8-53, (For peroxide value of fatty oils and acids).

Karadbhajne V.Y., and Gogte B/B., oct (2005) Journal of scientific and Industrial Research, vol $\underline{64}$, P. No. 752-755.

Gogte B.B., Oct. (2004) Journal of scientific and Industrial Research, vol 36, P. No.20-25.

Agrawal R.S., Kakadkar G, and Gogte B.B., (2003). Journal of soaps, Detergents and Toiletries Rev.,는 (5), P.No. 19-20-25.

Dontulwar J.R., and Gogte B.B., (2004). Asian Journal of Chemistry, Vol - 16 Nos, 3-4, P. No.1385-1390.

Kaustubh maynil, and Gogte B.B, (2007) . Journal of soaps, Detergents and Toiletries Rev., 38 (4), P.No. 25- 31.

Bhasin Prabhjot, and Gogte B.B, (2007). Journal of Chemical Product Finder, 26 (2), 59. 